\title{
a)
}

Asian Journal of Animal and Veterinary Advances

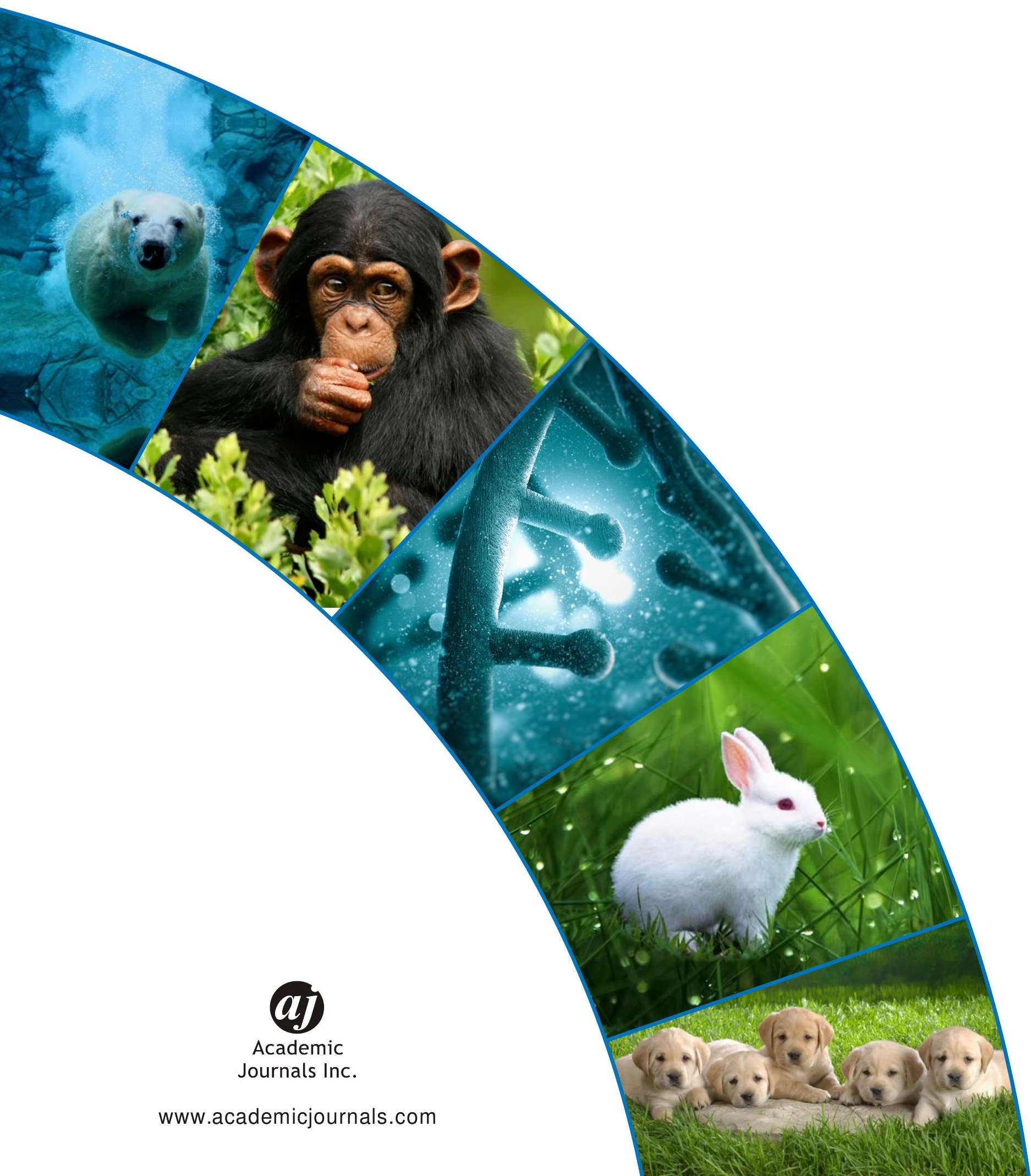




\title{
Research Article
}

\section{Osteogenesis Study of Hybrids of Indonesia's Native Chicken Pelung (Gallus gallus domesticus) with Broiler (Gallus gallus domesticus)}

\author{
${ }^{1}$ Bambang Retnoaji, ${ }^{1}$ Retno Wulandari, ' ${ }^{1}$ Luthfi Nurhidayat and ${ }^{2}$ Budi S. Daryono \\ ${ }^{1}$ Animal Structure and Development Laboratory, \\ ${ }^{2}$ Genetic and Breeding Laboratory, Faculty of Biology, Universitas Gadjah Mada, Jl. Teknika Selatan, Sekip Utara, Bulaksumur, \\ 55281 Yogyakarta, Indonesia
}

\section{Abstract}

Objective: To examine bone development and its growth of hybrid of Indonesian native chick-pelung-(Gallus gallus domesticus) and broiler (Gallus gallus domesticus) which was focused on anatomical and morphological properties of hybrid chick embryo's skeleton. Methods: Eggs were incubated for a different period, which were 5, 10, 14, 18 and 22 days and 7 weeks, respectively. Whole mounts embryo staining with alcian blue-alizarin red was conducted for the bone development and ossification study. Bone histological examination of ossification mechanism was prepared by paraffin method. The examinations were conducted by macroscopic and microscopic observation. Results: The result showed that ossification of Hybrid embryo was started at around incubation days 10 at the cranium, which then followed by extremity and were completed after 18 days of incubation at the vertebrae and long bone. Intramembranous ossification was accomplished more advanced compared to endochondral ossification. Conclusion: The ossification on hybrid chicken were started at 10 days stage and accomplished in the period of 18-22 days stage of embryo development, which following two osteogenesis mechanisms; intramembranous and endochondral bone formation.

Key words: Osteogenesis, chicken, Gallus gallus, new hybrid, broiler, pelung, native

Received: December 15, $2015 \quad$ Accepted: June 11, $2016 \quad$ Published: July 15, 2016

Citation: Bambang Retnoaji, Retno Wulandari, Luthfi Nurhidayat and Budi S. Daryono, 2016. Osteogenesis study of hybrids of Indonesia's native chicken pelung (Gallus gallus domesticus) with broiler (Gallus gallus domesticus). Asian J. Anim. Vet. Adv., 11: 498-504.

Corresponding Author: Bambang Retnoaji, Animal Structure and Development Laboratory, Faculty of Biology, Universitas Gadjah Mada, J. Teknika Selatan, Sekip Utara, Bulaksumur, 55281 Yogyakarta, Indonesia Tel: +62-274-480839 Fax: +62-274-480839

Copyright: ( $) 2016$ Bambang Retnoaji et al. This is an open access article distributed under the terms of the creative commons attribution License, which permits unrestricted use, distribution and reproduction in any medium, provided the original author and source are credited.

Competing Interest: The authors have declared that no competing interest exists.

Data Availability: All relevant data are within the paper and its supporting information files. 


\section{INTRODUCTION}

Bone a somite derivative is a very important compartment for body structure and function. Its organogenesis is occurring after the establishment of a primary and secondary body on embryo under the influenced of morfogens such as retinoic acid. The bone formation is innitiated by the formation of somite as transient structure, which were controlled by robust and rigorous mechanisms in very strict period and precise of size ${ }^{1-5}$. The Bone is provided at the place for muscle insertion, protection of an internal organ and body movement. Bone is known for its hardness, growth specific mechanisms and its capacity for regeneration. Moreover, bone is also providing the blood production and maturation.

Avian skeleton has the specific characteristic compare to other vertebrate for it's light, spongy and strong structure ${ }^{6}$. There are two specific types of bone in avian skeleton, which are pneumatic and medullar bones. The pneumatic bones are important for the respiratory process of the bird ${ }^{6,7}$. These bones are spongy in structure and directly connected to the respiratory system of the bird. The pneumatic bones are cranium, humerus, clavicle, sternum and also lumbar and sacral of vertebrae. On the other hand, medullar bones are important for its function to provide calcium for bird or chick. Calcium is the main component of egg shells and in order to build the shells, chicken use $47 \%$ of their body calcium. The medullar bones are the tibia, femur, ribs, ulna, digity and scapula ${ }^{6-8}$.

Aves share similar mechanisms during its formation and development where it by that most of the skeleton, form first as cartilage and sequentially ossified by the deposition of calcium. This mechanism of bone formation is known as endochondral bone formation and this kind of bone are known as cartilaginous bones. This is opposed to bone formation of intramembranous, which are ossified directly from mesodermal tissue and known as membranous bones ${ }^{9-11}$. The bone formation is directly related to the flesh mass increase in avian growth. The balance between the bone formation and the rate of flesh mass increase is very important in poultry field practices ${ }^{11,12-14}$.

New hybrid chicken resulted from Indonesia's native chicken pelung (Gallus gallus domesticus) with Broiler (Gallus gallus domesticus) was reported ${ }^{15}$. Until recently, no study on osteogenesis was conducted on the hybrid chicken. Therefore, it is important to understand the bone development and ossification processes, which is related to its body mass increase in hybrid chicken (Gallus gallus domesticus). In this study, we examine the bone development and ossification processes of both intramembranous and endochondral, which is compared to its body mass increase in hybrid Indonesia chicken.

\section{MATERIALS AND METHODS}

The experiment was conducted at Animal Structure and Development Laboratory, Faculty of Biology, Gadjah Mada University, Indonesia. The F1 Hybrid of Indonesian's native chicken pelung with broiler was used in this study. The eggs were divided into 6 groups with a total of 5 eggs for each group and incubated for several stages following previous research ${ }^{11}$. Thirty chick embryos were collected and used to investigate the bone development. The groups of embryos are as follows: Five days incubation, ten days incubation, fourteen days incubation, eighteen days incubation, one day after hatching and seven weeks old chickens, respectively. The eggs were hatched in artificial incubators with $37.5-38.0^{\circ} \mathrm{C}$ of temperature and $55-60 \%$ humidity and automatically reversed it's position every $2 \mathrm{~h}$.

Body mass and weight measurement: Body mass and weight measurement were conducted for every evaluation stage of embryos age. Eggs were weighted and dissected, the embryos were collected, cleaned and weighted then proceed to the next process.

\section{Bone development and ossification measurement}

Skeletal staining: Whole mounts embryo bone staining were conducted for this study. Embryos were fixed with 99\% ethanol for at least $48 \mathrm{~h}$ and internal organs were removed. They were treated with acetone for $24 \mathrm{~h}$ and then incubated in staining solution $(0.015 \%$ alcian blue, $0.015 \%$ alizarin red in $70 \%$ ethanol) at $37^{\circ} \mathrm{C}$ for 3-4 days. After being washed with water, the embryos were cleared using $1 \% \mathrm{KOH}$ for $48-72 \mathrm{~h}$ and successively incubated in $1 \% \mathrm{KOH}$ in $20 \%$ glycerol and $0.01 \% \mathrm{KOH}$ in $20 \%$ glycerol. Stained embryos were stored in $50 \%$ glycerol, examined and photographed.

Histological processing and observation: Histological structures of bone were prepared by paraffin section and stained with Hematoxylin-Eosin (HE) following standard method ${ }^{16}$. Femur bone and cranium of chicken embryos were sectioned at $6 \mu \mathrm{m}$ and observed for its bone structure (ossification stages).

Seven weeks age, bone measurements: Embryos were maintained for seven weeks and then weighted for whole body weight. The chick then sacrificed, bones of femur, tibia 
(a)

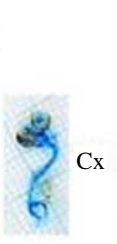

(b)
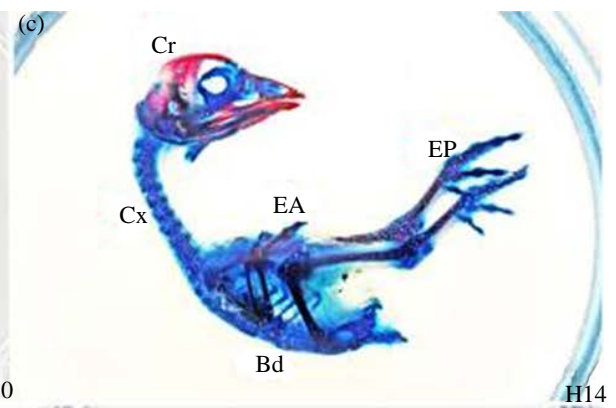

(d)

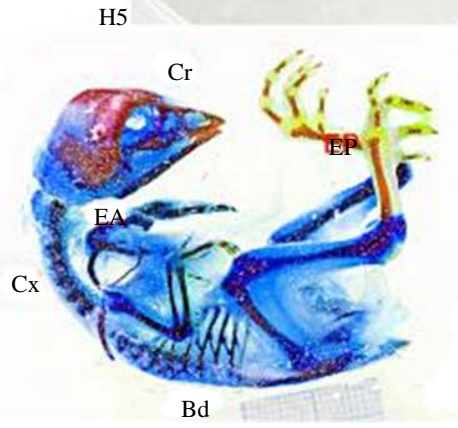

H10

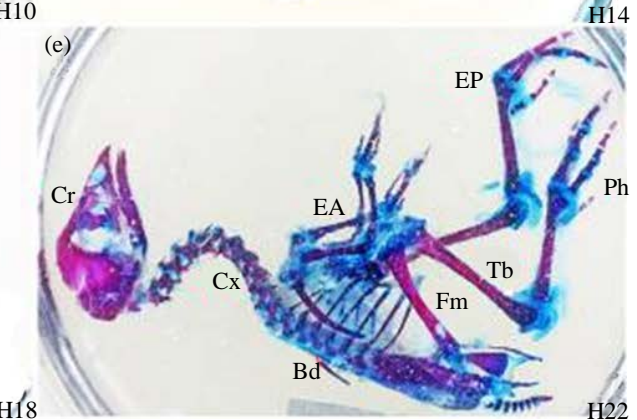

Fig. 1(a-e): Chick embryos at different stages, showing the ossification of embryo's bone (a) 5 days, (b) 10 days, (c) 14 days (d) 18 days and (e) 22 days, respectively, showing the bone ossification progression of hybrid chick embryo. Cranium $(\mathrm{Cr})$, body (Bd), Femur (Fm), Tibia ( $\mathrm{Tb})$, Phalanges (Ph), Cervix (Cx), Extremities (Ep and EA), alizarin red and alcian blue

and metatarsal were collected and weighted individually. The ratio of total body weight again bone was measured and noted.

Data analysis: Analysis of the data was conducted by qualitative and quantitative. Excel program was used for quantification of data based on visual observation of bone ossification.

\section{RESULTS}

Anatomy and morphology of embryo: To investigate what happens during the bone development, visual observation of embryo anatomy and morphology were conducted. Five days embryos shows incomplete formation of body compartment includes cranium, wing and leg, some bones structures such as the humerus, femur, pygostyle and vertebrae already formed. All embryos shows that all body skeletons were consist of cartilage, which was stained by alcian blue (Fig. 1a). Ten days embryos shows more developed embryos and almost complete of body compartment. Bones of maxilla, pre-maxilla, jugal, quadran, nasal, mandibula, cranialis and caudalis already formed. All embryos showed that all body skeletons were consist of cartilage (Fig. 1b).

Fourteen day's embryos show complete of body compartment and all bone started the ossification, except some cranial bone such as bosioccipital, basispenoid and orbitospenoid (Fig. 3). Eighteen and twenty two days embryos show all bones already stained by alizarin red, indicating complete bone calcification and well developed embryos (Fig. 1d). Some bones were extensively stained with alizarin red such as: Cranium (Cr), Vertebrae (Vrt), Rib (R), Femur (Fm), Tibia (Tb), Metatarsus (Mts), Phalanges (Ph) (Fig. 2 and 3). These bones are the main bone for forming body shape, locomotion and internal organ protection.

In order to understand the weight distribution on some pipe bone, we conducted measurement of bone such as femur, tibia and tars metatarsus. Moreover, this study also compare of each bone weight against the whole body weight to show the ratio of bone and total body weight. The result shows that the tibia is the heaviest pipe bone compare to others (supplementary Fig. 1 and 3).

Histological measurements: This study conducted histological examination of bone in order to understand the ossification processes of embryos (Fig. 4). The histological examination was conducted on 10 and 22 days embryo stage, which were prepared for proximal tibial physis and cranial bone, respectively. The histological examination showed two different type of bone formation, which are endochondral ossification on tibial physis and intramembranous ossification on cranial bone. Ten days stage of embryos shows hat ossification zone not yet clearly formed and the area is 


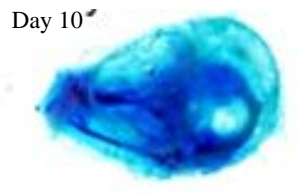

(a)

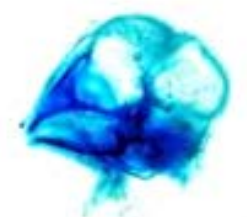

(b)

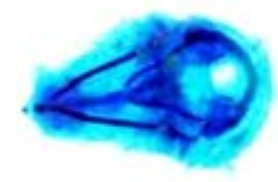

(c)

$$
\text { Ventral }
$$

Day 10

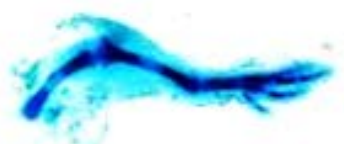

(j)

Day 14

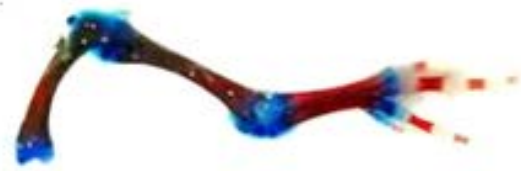

(1)

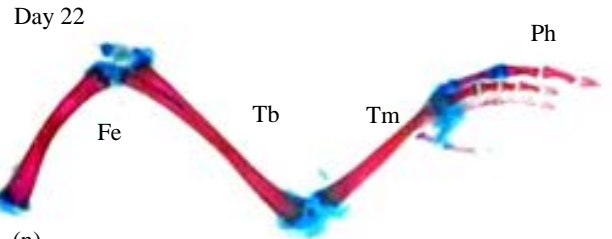

(n)

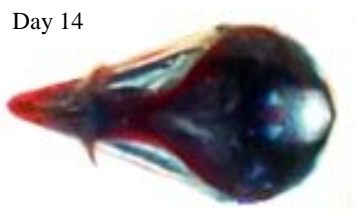

Dorsal

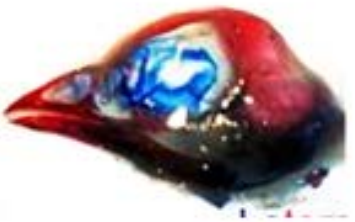

(e)

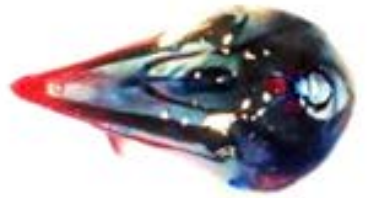

(f)

Ventral

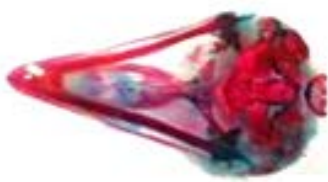

(i)

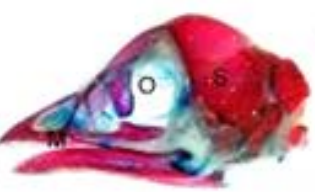

Lateral

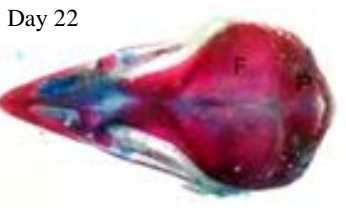

Dorsal

Day 10

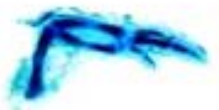

(k)

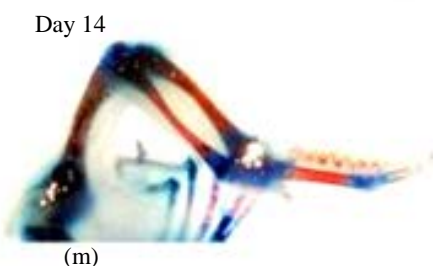

(m)

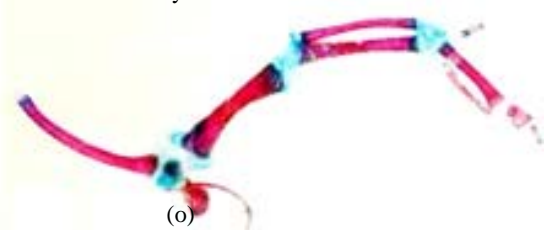

Fig. 2(a-o): Representative images of ossification progression of embryo's bone at 10, 14 and 22 days stages. Dorsal view of cranium $(a, d, g)$, Lateral view of cranium $(b, e, h)$, Ventral view of cranium $(c, f, i)$. Extremities bone $(j-o)$, alizarin red and alcian blue

composed of cartilage cells or matrix. On the other hand, 22 day's embryos stage show clear separation of the ossification zone (Fig. 4).

\section{DISCUSSION}

Bone formation of hybrid chicken in general is categorized on two mechanisms of formation which are:
Intramembranous bone formation with direct apposition of cortical bone by osteoblasts from the inner cambial layer of the periosteum and endochondral ossification the longitudinal bone growth and bone formation at the physeal-metaphyseal region.

Bone embryonic development started before day 5 of egg incubation, initiated by formation of part of vertebrae, extremities and cranial bone, in the form of 


\begin{tabular}{|c|c|c|c|c|c|}
\hline \multirow[b]{2}{*}{ Bone } & \multicolumn{5}{|c|}{ Embryo stage (days) } \\
\hline & 5 & 10 & 14 & 18 & 22 \\
\hline \multicolumn{6}{|l|}{ Cranial bone } \\
\hline \multicolumn{6}{|l|}{ Occipital } \\
\hline - Os Basioccipital & - & - & B & $\mathrm{R}$ & $\mathrm{R}$ \\
\hline - Os Exoccipital & - & B & $\mathrm{R}$ & $\mathrm{R}$ & $\mathrm{R}$ \\
\hline - Os Supraoccipital & - & - & $\mathrm{B}$ & $\mathrm{R}$ & $\mathrm{R}$ \\
\hline \multicolumn{6}{|l|}{ Sphenoid } \\
\hline - Os Basisphenoid & - & B & B & $\mathrm{R}$ & $\mathrm{R}$ \\
\hline - Os Parasphenoid & - & - & $\mathrm{B}$ & $\mathrm{R}$ & $\mathrm{R}$ \\
\hline - Os Orbitosphenoid & - & B & $\mathrm{B}$ & $\mathrm{R}$ & $\mathrm{R}$ \\
\hline Parietal & - & - & $\mathrm{R}$ & $\mathrm{R}$ & $\mathrm{R}$ \\
\hline Prefrontal & - & - & B & $\mathrm{R}$ & $\mathrm{R}$ \\
\hline Frontal & - & - & $\mathrm{R}$ & $\mathrm{R}$ & $\mathrm{R}$ \\
\hline Maxilla & - & B & $\mathrm{R}$ & $\mathrm{R}$ & $\mathrm{R}$ \\
\hline Premexilla & - & $\mathrm{B}$ & $\mathrm{R}$ & $\mathrm{R}$ & $\mathrm{R}$ \\
\hline Pterygoid & - & - & $\mathrm{R}$ & $\mathrm{R}$ & $\mathrm{R}$ \\
\hline Jugal & - & B & $\mathrm{R}$ & $\mathrm{R}$ & $\mathrm{R}$ \\
\hline Quadratum & - & $\mathrm{B}$ & $\mathrm{R}$ & $\mathrm{R}$ & $\mathrm{R}$ \\
\hline Nasal & - & $\mathrm{B}$ & $\mathrm{R}$ & $\mathrm{R}$ & $\mathrm{R}$ \\
\hline Mandibula & - & B & $\mathrm{R}$ & $\mathrm{R}$ & $\mathrm{R}$ \\
\hline Dentary & - & B & $\mathrm{R}$ & $\mathrm{R}$ & $\mathrm{R}$ \\
\hline Angular & - & B & $\mathrm{R}$ & $\mathrm{R}$ & $\mathrm{R}$ \\
\hline \multicolumn{6}{|l|}{ Extremities } \\
\hline Scapula & - & B & $\mathrm{R}$ & $\mathrm{R}$ & $\mathrm{R}$ \\
\hline Clavicula & - & B & $\mathrm{R}$ & $\mathrm{R}$ & $\mathrm{R}$ \\
\hline Coracoid & - & B & $\mathrm{R}$ & $\mathrm{R}$ & $\mathrm{R}$ \\
\hline Humerus & B & B & $\mathrm{R}$ & $\mathrm{R}$ & $\mathrm{R}$ \\
\hline Radius & - & $\mathrm{B}$ & $\mathrm{R}$ & $\mathrm{R}$ & $\mathrm{R}$ \\
\hline Ulna & - & $\mathrm{B}$ & $\mathrm{R}$ & $\mathrm{R}$ & $\mathrm{R}$ \\
\hline Metacarpus & - & $\mathrm{B}$ & $\mathrm{R}$ & $\mathrm{R}$ & $\mathrm{R}$ \\
\hline Phalanges & B & B & $\mathrm{R}$ & $\mathrm{R}$ & $\mathrm{R}$ \\
\hline \multicolumn{6}{|l|}{ Vertebrae } \\
\hline • Cervic & B & B & $\mathrm{R}$ & $\mathrm{R}$ & $\mathrm{R}$ \\
\hline - Thorac & B & B & $\mathrm{R}$ & $\mathrm{R}$ & $\mathrm{R}$ \\
\hline - Lumbar & B & B & $\mathrm{R}$ & $\mathrm{R}$ & $\mathrm{R}$ \\
\hline - Sacral & $\mathrm{B}$ & $\mathrm{B}$ & $\mathrm{R}$ & $\mathrm{R}$ & $\mathrm{R}$ \\
\hline \multicolumn{6}{|l|}{ Caudal extremities bones } \\
\hline Illium & - & B & $\mathrm{R}$ & $\mathrm{R}$ & $\mathrm{R}$ \\
\hline Isehium & - & B & $\mathrm{R}$ & $\mathrm{R}$ & $\mathrm{R}$ \\
\hline Pygostyle & B & B & B & $\mathrm{R}$ & $\mathrm{R}$ \\
\hline Pubis & - & B & $\mathrm{R}$ & $\mathrm{R}$ & $\mathrm{R}$ \\
\hline Femur & B & B & $\mathrm{R}$ & $\mathrm{R}$ & $\mathrm{R}$ \\
\hline Tibia & - & $\mathrm{R}$ & $\mathrm{R}$ & $\mathrm{R}$ & $\mathrm{R}$ \\
\hline Metatarsus & - & $\mathrm{B}$ & $\mathrm{R}$ & $\mathrm{R}$ & $\mathrm{R}$ \\
\hline Phalanges & B & B & $\mathrm{R}$ & $\mathrm{R}$ & $\mathrm{R}$ \\
\hline
\end{tabular}

Fig. 3: List of bone and ossification status bones, R (red) and cartilage, B (blue) are stained by alizarin red and alcian blue, respectively

cartilage, respectively. Data showed that at this stage the calcification of bone didn't start yet. This is in contrast to previous findings by Sawad et al. ${ }^{11}$ as they found that the chick already started the calcification of femur bone on day 5.

The observation on embryos at 10th days incubation showed that all body parts of the embryo already formed and body skeleton were mainly consist of cartilage. However, ossification has already started at long bone of the tibia, that the same findings of Mitgutsch et al. ${ }^{17}$ in Anas platyrhynchos and in Coturnix coturnix japonica and disagreement with Maxwell and Larsson $^{18}$ in Rhea americana, which bone ossification was started at day 14 th. The next ossification were on scapulae and clavicle, which than followed by vertebral arches of the cervical, thoracic and lumbar bone.

At 14th days stage, almost all parts of bone already calcified which was marked alizarin red staining, except for occipital, sphenoid, prefrontal and pygostyle bones, which remained on cartilaginous stage. This observation is in agreement with the report of Sawad et al. ${ }^{11}$ in Gallus gallus and Maxwell ${ }^{19}$ in Rhea americana.

At 18th and 22nd days stage all part of bone already completely calcified. This finding suggest that, 10-14 day's embryos stage seem to be the period of transformation of body skeleton, from cartilage to ossified bone. This is in line with the finding of Namba et al..20, on the white leghorn chicken (Gallus gallus). In this period the embryos also show more developed and all body organs were completely formed, including all extremities.

The observations carried out on the histological slide of 22nd days stage embryo, shows the occurrence of the ossification zone in physeal-metaphyseal area, which are: Resting zone, proliferative zone, hypertrophic zone, calcified zone and ossification zone. That finding is in agreements with the report of Ahmed and Soliman ${ }^{21}$, on Japanese quail, Smith ${ }^{22}$ on chick embryo and Ahmed et a/.23 on Japanese quail 1 day post hatching. However, this zonation couldn't be observed in 10 days embryo stages, which is in agreement with Fratini et al. ${ }^{24}$, on Brazilian domestic chicken 


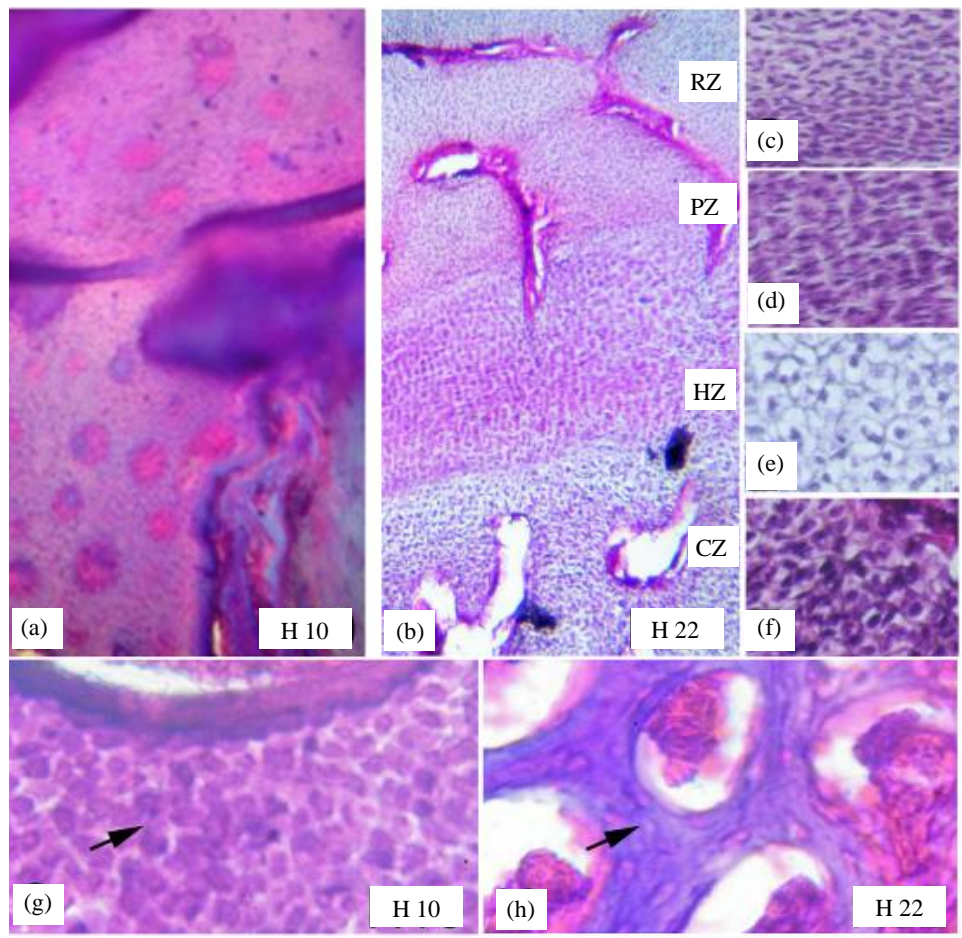

Fig. 4(a-h): Histological structure of flat and pipe bone of Chick embryos at 10 and 22 days, respectively. Femur epiphyses of (a) 10 days stage embryo, showing no ossification zone (b) 22 days stage embryo, showing ossification zone, (c) RZ: Zone of resting cartilage, (d) PZ: Zone of proliferating cartilage, (e) HZ: Zone of hyperthtopic cartilage, ( $f$ ) CZ: Zone of calcified cartilage, (g) Cranium bone of 10 days embryo and (h) 22 days embryo stage. Haematoxylin-Eosin staining

(Gallus gallus domesticus). This result suggests that bone ossification didn't start until 10 days stage of the embryo. Therefore, the formation of the ossification zone in hybrid chicken had possibly started after 10 days stages and continue during it is proceeding development until post hatching period on 22 days stage, where the chick bone strength already achieved its full function for chick mobility. This finding is supported by report of Smith ${ }^{22}$, which showed the existence of ossification zone on a 16th day stage of the chick embryo.

The 22 days stage embryo alizarin red and alcian blue staining result presented above also showed that the mineralization of bone in the form of hydroxyapatite, provides stiffness and strength to avian bone, which are very useful for mobility and flight activity of the bird and usually occurs along the development of the embryo $0^{11,13,25,26}$.

\section{CONCLUSION}

In conclusion, the ossification on hybrid chicken were started at 10 days stage and accomplished at the period of 18-22 days stage of embryo development, which following two osteogenesis mechanisms; intramembranous and endochondral bone formation.

\section{ACKNOWLEDGMENTS}

Authors are grateful to all contributors for sharing reagents, helpful discussions and critical reading of the manuscript and for technical assistance. This study was supported by Grants BOPTN-KP4 Gadjah Mada University, 2013 and Hibah Penulisan Karya Internasional, UGM 2015.

\section{REFERENCES}

1. Rutten, M., C. Leterrier, P. Constantin, K. Reiter and W. Bessei, 2002. Bone development and activity in chickens in response to reduced weight-load on legs. Anim. Res., 51: 327-336.

2. Junqueira, L.C. and J.Carneiro, 2005. Basic Histology: Text and Atlas. 3rd Edn., McGraw-Hill, USA., ISBN: 9780071440912, Pages: 544.

3. Samuelson, D.A., 2007. Textbook of Veterinary Histology. Saunders-Elsevier, Missouri, USA., ISBN-13: 9780721681740, Pages: 546. 
4. Mills, S.E., 2007. Histology for Pathologists. 3rd Edn., Lippincott Williams and Wilkins, USA., ISBN-13: 9780781762410, Pages: 1272.

5. Retnoaji, B., R. Akiyama, T. Matta, Y. Bessho and T. Matsui, 2014. Retinoic acid controls proper head-to-trunk linkage in zebrafish by regulating an anteroposterior somitogenetic rate difference. Development, 141: 158-165.

6. Jacob, J. and T. Pescatore, 2011. The avian skeletal system. ASC-202, Cooperative Extension Service, University of Kentucky, Lexington, KY., USA. http://www2.ca.uky.edu/agcomm/pubs/ASC/ASC202/ASC 202.pdf

7. Maina, J.N., 2000. Comparative respiratory morphology: Themes and principles in the design and construction of the gas exchangers. Anatom. Rec., 261: 25-44.

8. Dumont, E.R., 2010. Bone density and the lightweight skeletons of birds. Proc. R. Soc. London B: Biol. Sci., 277: 2193-2198.

9. Nakane, Y. and M. Tsudzuki, 1999. Development of the skeleton in Japanese quail embryos. Dev. Growth Differ., 41: 523-534.

10. Reddi, A.H., 2000. Initiation and promotion of endochrondral bone formation by bone morphogenetic proteins: Potential implications for avian tibial dyschondroplasia. Poult. Sci., 79: 978-981.

11. Sawad, A.A., B.A. Hana and A.N.Al-Silawi, 2009. Morphological study of the skeleton development in chick embryo (Gallus domesticus). Int. J. Poult. Sci., 8: 710-714.

12. Shapiro, F., 2008. Bone development and its relation to fracture repair. The role of mesenchymal osteoblasts and surface osteoblasts. Eur. Cell Mater., 15: 53-76.

13. Rath, N.C., G.R. Huff, W.E. Huff and J.M. Balog, 2000. Factors regulating bone maturity and strength in poultry. Poult. Sci., 79: 1024-1032.

14. Di Nino, D.L., F. Long and T.F. Linsenmayer, 2001. Regulation of endochondral cartilage growth in the developing avian limb: Cooperative involvement of perichondrium and periosteum. Dev. Biol., 240: 433-442.

15. Saragih, H., B.S. Daryono and Sasongko, 2009. The Improvement of native chicken performance by Genetic improvement. Research Report, Gadjah Mada University, Indonesia.
16. Bancroft, J.D. and H.C. Cook, 1988. Manual of Histological Techniques. Churchill Livingstone, New York, pp: 18-20.

17. Mitgutsch, C., C. Wimmer, M.R. Sanchez-Villagra, R. Hahnloser and R.A. Schneider, 2011. Timing of ossification in duck, quail and zebra finch: Intraspecific variation, heterochronies and life history evolution. Zool. Sci., 28: 491-500.

18. Maxwell, E.E. and H.S.C. Larsson, 2009. Comparative ossification sequence and skeletal development of the postcranium of palaeognathous birds (Aves: Palaeognathae). Zool. J. Linnean Soc., 157: 169-196.

19. Maxwell, E.E., 2009. Comparative ossification and development of the skull in palaeognathous birds (Aves: Palaeognathae). Zool. J. Linnean Soc., 156: 184-200.

20. Namba, Y., Y. Yamazaki, M. Yuguchi, S. Kameoka, S. Usami, K. Honda and K. Isokawa, 2010. Development of the Tarsometatarsal skeleton by the lateral fusion of three cylindrical periosteal bones in the chick embryo (Gallus gallus). Anatom. Rec., 293: 1527-1535.

21. Ahmed,Y.A. and S.A. Soliman, 2013. Long bone development in the Japanese Quail (Coturnix coturnix Japonica) embryos. Pak. J. Biol. Sci., 16: 911-919.

22. Smith, E.L., J.M. Kanczler and R.O. Oreffo, 2013. A new take on an old story: Chick limb organ culture for skeletal niche development and regenerative medicine evaluation. Eur. Cells Mater., 26: 91-106.

23. Ahmed, Y.A., S.A. Soliman and E.A. Abdel-Hafez, 2013. Ossification of the femur and tibia of the post-hatching Japanese quail. Pak. J. Biol. Sci., 16: 859-864.

24. Fratini, P., D. Alcantara, M.N. Rodrigues, F.M. de Oliveira e Silva and A.L.R. Rezende Franciolli et al., 2013. Osteogenesis in chicken (Gallus gallus domesticus) and expression of VEGF in this process between $5^{\circ}$ to $19^{\circ}$ days of incubation. J. Cytol. Histol., Vol. 4. 10.4172/2157-7099.1000178

25. Korver, D.R., 2004. Modern poultry production and avian bone biology. Proceedings of the 16th Australian Poultry Science Symposium, February 9-11, 2004, Sydney, New South Wales, Australia, pp: 108-111.

26. Fleming, R.H., 2008. Nutritional factors affecting poultry bone health. Proc. Nutr. Soc., 67: 177-183. 